\title{
Protective effects of dexmedetomidine combined with flurbiprofen axetil on remifentanil-induced hyperalgesia: A randomized controlled trial
}

\author{
ZENGGUI YU ${ }^{1,2}$, WEILAN WU ${ }^{2}$, XIAODAN WU ${ }^{2}$, HONGYI LEI ${ }^{1}$, CANSHENG GONG $^{2}$ and SHIYUAN XU ${ }^{1}$ \\ ${ }^{1}$ Department of Anesthesiology, Zhujiang Hospital of Southern Medical University, Guangzhou, Guangdong 510280; \\ ${ }^{2}$ Department of Anesthesiology, Fujian Provincial Hospital, Fuzhou, Fujian 350001, P.R. China
}

Received July 1, 2015; Accepted August 23, 2016

DOI: $10.3892 / \mathrm{etm} .2016 .3687$

\begin{abstract}
High dosages of intra-operative remifentanil are associated with opioid-induced hyperalgesia $(\mathrm{OIH})$. The aim of the present study was to investigate the effect of combined dexmedetomidine and flurbiprofen axetil treatment on remifentanil-induced hyperalgesia. Patients with an American Society of Anesthesiologists physical status of I-II who were diagnosed with hysteromyoma and scheduled for laparoscopic assisted vaginal hysterectomy (LAVH) were randomly divided into three groups. Group hyperalgesia (Group H, n=29) received intra-operative remifentanil, Group hyperalgesia and dexmedetomidine (Group HD, n=28) received remifentanil and a continuous infusion of dexmedetomidine, and Group hyperalgesia, dexmedetomidine and flurbiprofen axetil (Group HDF, $n=29$ ) received remifentanil, flurbiprofen axetil and dexmedetomidine. Mechanical pain thresholds were measured during the preoperative visit and postoperatively at 1, 6 and 24-h time points. Visual analog scale (VAS) scores, time to analgesic requirement, total sufentanil consumption and side effects were assessed postoperatively. Mechanical pain threshold at the incision site was significantly lower in Group H compared with Groups HD and HDF (both $\mathrm{P}<0.05$ ), and significantly higher in Group HDF than in Group HD $(\mathrm{P}<0.05)$. The area of secondary hyperalgesia at the incision site was greater in Group $\mathrm{H}$ than in the other two groups (both $\mathrm{P}<0.05)$, and significantly smaller in Group HDF compared with Group HD $(\mathrm{P}<0.05)$. VAS scores and total sufentanil consumption were significantly higher in Group $\mathrm{H}$ compared with the other two groups (both $\mathrm{P}<0.05$ ), and were significantly lower in Group HDF compared with Group HD $(\mathrm{P}<0.05)$. Dexmedetomidine combined with flurbiprofen axetil exhibits
\end{abstract}

Correspondence to: $\mathrm{Dr}$ Shiyuan $\mathrm{Xu}$, Department of Anesthesiology, Zhujiang Hospital of Southern Medical University, 253 Industrial Road, Guangzhou, Guangdong 510280, P.R. China E-mail: shiyuanxu355@163.com

Key words: dexmedetomidine, flurbiprofen axetil, opioid induced hyperalgesia, remifentanil synergetic effects in the prevention of remifentanil-induced hyperalgesia in patients undergoing LAVH.

\section{Introduction}

It has been well-documented that opioid-induced hyperalgesia $(\mathrm{OIH})$ is a potential risk factor for the development of chronic pain following surgery based on the results from basic and clinical studies (1-4). Many patients undergoing surgery experience moderate to severe acute postoperative pain possibly caused by $\mathrm{OIH}$ in addition to inflammatory and neuropathic pain (1). OIH is defined as a state of nociceptive sensitization characterized by a paradoxical response, in which a patient receiving opioids to treat pain might have an increased sensitivity to painful stimuli (2). In a systematic review and meta-analysis, Fletcher and Martinez concluded that exposure to a high dose of short-acting remifentanil was associated with the development of hyperalgesia and led to significantly increased acute pain after surgery (3).

Although OIH is generally caused by neuroplastic changes in the peripheral and central nervous system, the precise molecular mechanism of OIH is not well understood (4). A cellular mechanism involving the rapid and prolonged upregulation of N-methyl-D-aspartate (NMDA) receptor function by remifentanil has been reported to contribute to the clinical development of remifentanil-induced hyperalgesia (5). Modulation of acute $\mathrm{OIH}$ has been reported with NMDA receptor antagonists, $\alpha_{2}$ agonists and cyclooxygenase (COX) inhibitors in clinical studies, as previously reviewed (6). Data from basic research have shown that dexmedetomidine produces antihyperalgesic effects by inhibiting the phosphorylation of NMDA receptor subunit $2 \mathrm{~B}(\mathrm{NR} 2 \mathrm{~B})$, and that increased tyrosine phosphorylation of NR2B in the spinal cord is associated with remifentanil-induced postoperative hyperalgesia (7).

Another proposed mechanism for the regulation of NMDA receptor function involves $\mathrm{COX}$ inhibitors. $\mathrm{COX}$ inhibitors have been found to antagonize the NMDA receptor, inhibit the synthesis of prostaglandin (PGs), and thereby reduce the production of inflammatory mediators and decrease peripheral sensitization (8). PGs have been shown to stimulate the release of the excitatory amino acid glutamate in spinal cord dorsal horns (9) and promote NMDA receptor activation (10), 
which is one of the main mechanisms of remifentanil-induced hyperalgesia (11). In summary, the mechanisms of both $\alpha_{2}$ adrenergic receptor agonists and COX inhibitors in preventing OIH probably involve the regulation of NMDA receptors.

Thus, the present study examined the hypothesis that $\alpha_{2}$ adrenergic receptor agonists and COX inhibitors would have synergetic effects on preventing the hyperalgesia induced by high-dose remifentanil in patients. This study aimed to compare the effect of using dexmedetomidine alone or combined with flurbiprofen axetil in reducing the hyperalgesic response after high-dose infusion of remifentanil in patients undergoing laparoscopic-assisted vaginal hysterectomy (LAVH).

\section{Materials and methods}

Study subjects. This study was approved by the Ethics Committee of Fujian Provincial Hospital (Fujian, China) and registered (ChiCTR-TRC-14004837) at Chictr.org. After written informed consent was obtained, 95 adult women aged from 18 to 60 years, with American Society of Anesthesiologists physical status I or II, who were diagnosed with hysteromyoma and underwent elective LAVH were enrolled in this study. Patients who met the inclusion criteria $(n=90)$ were randomly divided into three groups (each $n=30$ ) using a computer-generated random number table. The exclusion criteria included narcotic analgesic abuse, opioid-related medication, morbid obesity, contradictory to patient-controlled intravenous analgesia (PCIA), allergy to dexmedetomidine or flurbiprofen axetil and significant psychiatric conditions. A day before surgery, all patients were instructed about the use of a 100-mm linear visual analog scale (VAS) and patient-controlled analgesia (PCA) device (Apollo Science Instrument Co., Ltd., Jiangsu, China). They were instructed to perform a self-delivered analgesia procedure once they felt pain. The quantitative sensory testing (QST) procedure using an Electronic von Frey (EVF) device (IITC Life Science Inc., Woodland Hills, CA, USA) was carefully explained in detail by an anesthesiologist who was not aware of the grouping.

Intervention protocols. Patients were sedated with midazolam (2-3 mg) upon arrival at the operating room and standard monitoring and bispectral index (BIS) monitoring (BIS Vista; Medtronic, Minneapolis, MN, USA) were performed. At $15 \mathrm{~min}$ prior to anesthesia induction, the hyperalgesia and dexmedetomidine group (Group HD) were given a continuous infusion of dexmedetomidine (Hengrui Pharmaceutical Co., Ltd., Lianyungang, China) as an initial dose of $0.5 \mu \mathrm{g} / \mathrm{kg}$ within $10 \mathrm{~min}$, followed by a continuous infusion of $0.6 \mu \mathrm{g} / \mathrm{kg} / \mathrm{h}$, and the hyperalgesia, dexmedetomidine and flurbiprofen axetil group (Group HDF) received flurbiprofen axetil $(1.5 \mathrm{mg} / \mathrm{kg}$; Tide Pharmaceutical Co., Ltd., Beijing, China) $10 \mathrm{~min}$ before anesthesia induction in combination with dexmedetomidine infusion. The remaining patients constituted the hyperalgesia group (Group H). Anesthesia was induced with an inhalation agent. The anesthetic circuit of the ventilator was prefilled with 7\% sevoflurane (Maruishi Pharmaceutical Co., Ltd., Chuoku, Japan) in $7 \mathrm{l} / \mathrm{min}$ oxygen for $3 \mathrm{~min}$. Induction was then performed with the vital capacity rapid inhalation induction technique. Following a deep exhalation to the residual volume, patients were asked to take a forced inspiration, to hold it as long as possible and then to breathe spontaneously or with assisted ventilation. At 2 min after the beginning of induction, fresh gas flow was reduced to $4 \mathrm{l} / \mathrm{min}$ and sevoflurane was set to a rate of $3 \%$. Remifentanil $(1 \mu \mathrm{g} / \mathrm{kg}$; Humanwell Pharmaceutical Co., Ltd., Yichang, China) was then administered over $1 \mathrm{~min}$ followed by an infusion of $0.5 \mu \mathrm{g} / \mathrm{kg} / \mathrm{min}$. When the BIS value was $<50$, rocuronium $(0.9 \mathrm{mg} / \mathrm{kg}$; NV Organon, Oss, The Netherlands) was administered intravenously to facilitate intubation. After tracheal intubation, anesthesia was maintained with intravenous remifentanil infusion at $0.3 \mu \mathrm{g} / \mathrm{kg} / \mathrm{min}$ and sevoflurane inhalation. The concentration of sevoflurane was adjusted $(0.5 \%$ stepwise titration) according to the target BIS between 40 and 60 . The continuous infusion of dexmedetomidine in Groups HD and HDF was terminated at $30 \mathrm{~min}$ prior to the end of surgery, while the remifentanil infusion in all groups was continued until the final stitch. If hypotension (mean arterial pressure, $<60 \mathrm{~mm} \mathrm{Hg}$ ) or bradycardia (heart rate, $<45$ beats/min) occurred more than 5 min after fluid resuscitation, the patient was treated with $10 \mathrm{mg}$ ephedrine or $0.5 \mathrm{mg}$ atropine. For prophylaxis of postoperative nausea and vomiting (PONV), 4 mg ondansetron (Tianheng Pharmaceutical Co., Ltd., Ningbo, China) was given intravenously 15 min before the end of surgery. Upon completion of surgery, neuromuscular blockade was reversed with $1 \mathrm{mg}$ neostigmine and $0.5 \mathrm{mg}$ atropine intravenously. After the recovery of adequate spontaneous ventilation and a response to verbal commands such as eye opening, extubation was performed. A PCIA pump was applied to all patients when the surgery was completed. The PCIA pump contained sufentanil (150 $\mu \mathrm{g}$; Humanwell Pharmaceutical Co., Ltd.), ondansetron (8 mg) and normal saline in a total volume of $100 \mathrm{ml}$, and was set to deliver a 2-ml bolus dose with a 10-min lockout interval with a background infusion of $1 \mathrm{ml} / \mathrm{h}$. The patients were transferred to the post-anesthesia care unit, where the VAS pain scores at $30 \mathrm{~min}$ and $1 \mathrm{~h}$ after surgery were evaluated and the mechanical pain threshold was recorded at $1 \mathrm{~h}$ after surgery. If the patient sought more extensive pain control or if the VAS score was $>6$, sufentanil $5 \mu \mathrm{g}$ was administered as a rescue dose.

Outcome measurements. Primary outcomes were the mechanical pain threshold and the area of secondary hyperalgesia at $24 \mathrm{~h}$ after surgery. The mechanical pain threshold was determined using an EVF device (rigid tips) on the midpoint of the inner forearm, $2 \mathrm{~cm}$ above the level of the umbilicus (preoperative) and $2 \mathrm{~cm}$ from the incision site (around the umbilicus, postoperative) at four points (horizontally and perpendicularly). The rigid tip of the probe was pressed at a right angle and force exerted against the testing area within the patient's tolerance. The probe was removed when the patient perceived pain, and the compact system automatically stored and displayed the testing results. The area of secondary hyperalgesia was tested with the rigid tip around the surgical incision. It was determined by testing along linear paths, quadrilaterally at a distance of $5 \mathrm{~cm}$ around the incision at $24 \mathrm{~h}$ after surgery. Along linear paths, stimulation attempts started at $5 \mathrm{~cm}$ from the incision site and gradually moved toward the site, moving $0.5 \mathrm{~cm}$ closer each time. Each attempt was applied with increasing force until a readout value of $\sim 30 \mathrm{~g}$ was reached ( $30 \mathrm{~g}$ was defined as the hyperalgesic pain threshold) and stopped when the patient 


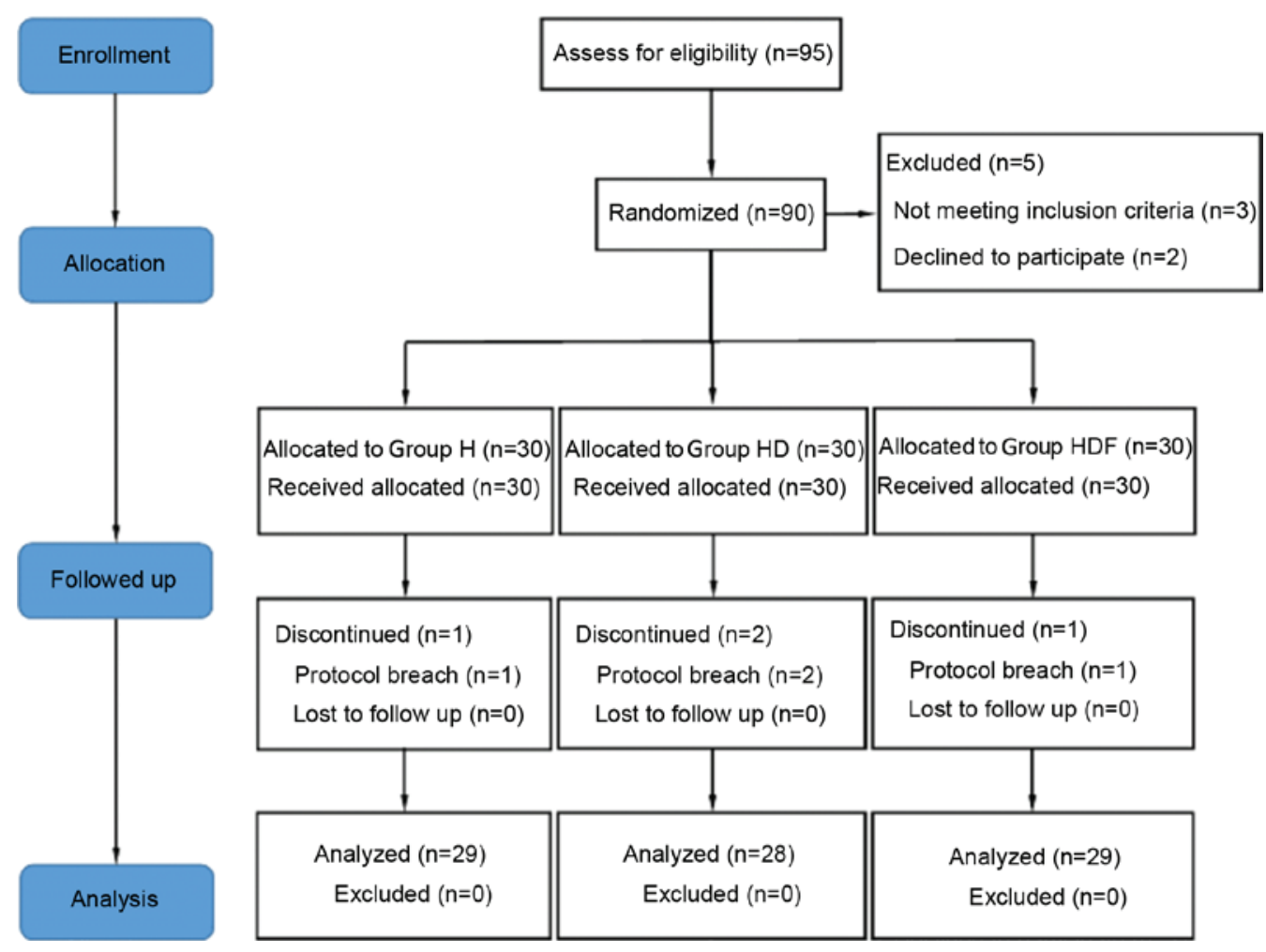

Figure 1. Consolidated Standards of Reporting Trials flowchart. Group H, high dose of remifentanil ( $0.3 \mu \mathrm{g} / \mathrm{kg} / \mathrm{min})$; Group HD, high dose of remifentanil $(0.3 \mu \mathrm{g} / \mathrm{kg} / \mathrm{min})$ plus dexmedetomidine; Group HDF, high dose of remifentanil $(0.3 \mu \mathrm{g} / \mathrm{kg} / \mathrm{min})$ plus dexmedetomidine and flurbiprofen axetil.

perceived pain. The stimulation was stopped $1 \mathrm{~cm}$ from the incision if no change in sensation occurred. The distance from the incision to where sensations changed was measured, and an average of four assessments was calculated and used for statistical comparisons. The hyperalgesic area (A) was calculated using the formula: $A=\pi r^{2}$, where $r$ was the average distance to the site. The secondary outcomes included time to first analgesic requirement, postoperative analgesic consumption, VAS pain score, and incidence of associated side effects including PONV, hypotension, bradycardia and post-anesthetic shivering. General assessments include demographic characteristics (age, weight and height), awakening and extubation time (defined as time from remifentanil discontinuation to patients' responses to a verbal command and extubation, respectively), dose of remifentanil, volume of sevoflurane and duration of anesthesia and surgical procedure.

Statistical analysis. All data were processed using Statistical Package for Social Sciences (SPSS) software, version 20.0 (IBM SPSS, Armonk, NY, USA). The normality of distribution for each variable was verified using the Shapiro-Wilk test. Numeric variables were described as the mean \pm standard deviation or median (interquartile range, IQR) while categorical variables were expressed as number (percentage, \%). The demographic characteristics, surgery-related information and time to first analgesic requirement were analyzed using one-way analysis of variance, with post hoc Bonferroni corrections. Two-way repeated measures analysis of variance followed by post hoc Bonferroni corrections was used to analyze the difference between the treatments at different time points. For analgesic-related adverse effects, differences between groups were compared with Chi-square or Fisher's exact test, and pairwise Kruskal-Wallis $\mathrm{H}$ test was used to further analyze the deviation between groups. $\mathrm{P}<0.05$ was considered to indicate a statistically significant difference. Power calculation indicated that to yield a power of $80 \%$ with a significance level of $5 \%$ based on the $20 \%$ reduction in hyperalgesic area from a preliminary experiment, there should be $\geq 26$ subjects in each group.

\section{Results}

Recruitment and clinical characteristics of patients in the three groups. Of the 95 recruited participants, 5 patients were declined during eligibility assessments for not meeting the inclusion criteria. A total of 90 patients were considered eligible and received study medication following randomization. Four of the 90 patients initially enrolled were withdrawn because of conversion to open surgery. The remaining 86 patients completed the study and were included in the statistical analysis (Fig. 1). There were no significant differences in age, weight, height, duration of anesthesia and surgery, awakening time, extubation time and remifentanil consumption among the three groups (Table I). The mean volume (\%) of sevoflurane was significantly lower in Group HD and Group HDF compared with Group H (both $\mathrm{P}<0.05$ vs. Group H; Table I).

Per-incisional mechanical pain threshold around the umbilicus and postoperative pain score measured using a VAS. The mechanical pain threshold at the midpoint of the inner 
Table I. Patient demographic characteristics and surgery-related parameters.

\begin{tabular}{lccc}
\hline Variables & Group H $(\mathrm{n}=29)$ & Group HD (n=28) & Group HDF (n=29) \\
\hline Age (year) & $45.8 \pm 3.6$ & $45.9 \pm 2.9$ & $46.7 \pm 4.9$ \\
Weight (kg) & $58.4 \pm 8.7$ & $59.8 \pm 7.8$ & $60.0 \pm 6.2$ \\
Height (cm) & $159.3 \pm 5.0$ & $158.4 \pm 4.6$ & $160.4 \pm 3.9$ \\
Duration of anesthesia (min) & $135.6 \pm 18.3$ & $138.3 \pm 20.6$ & $129.6 \pm 18.9$ \\
Duration of surgery (min) & $117.1 \pm 17.0$ & $121.1 \pm 20.6$ & $113.2 \pm 16.2$ \\
Awakening time (min) & $13.0 \pm 3.6$ & $14.6 \pm 3.7$ & $14.2 \pm 3.5$ \\
Extubation time (min) & $13.7 \pm 3.5$ & $15.1 \pm 3.4$ & $14.7 \pm 3.5$ \\
Remifentanil consumption $(\mu \mathrm{g})$ & $2,442.1 \pm 541.5$ & $2,524.9 \pm 476.9$ & $2,388.2 \pm 381.1$ \\
Mean volume of sevoflurane $(\%)$ & $1.59 \pm 0.17$ & $1.20 \pm 0.16^{\mathrm{a}}$ & $1.13 \pm 0.19^{\mathrm{a}}$ \\
\hline
\end{tabular}

Values are expressed as mean \pm standard deviation. Group H, high dose of remifentanil $(0.3 \mu \mathrm{g} / \mathrm{kg} / \mathrm{min})$; Group HD, high dose of remifentanil $(0.3 \mu \mathrm{g} / \mathrm{kg} / \mathrm{min})$ plus dexmedetomidine; Group HDF, high dose of remifentanil $(0.3 \mu \mathrm{g} / \mathrm{kg} / \mathrm{min})$ plus dexmedetomidine and flurbiprofen axetil. ${ }^{\mathrm{a}} \mathrm{P}<0.05$ vs. Group H.

forearm was not significantly different among the three groups at the preoperative and 1,6 and $24 \mathrm{~h}$ postoperative time points, respectively (data not shown). Mechanical pain threshold at the incision site was not significantly different among the three groups preoperatively, but was significantly lower at 1, 6 and $24 \mathrm{~h}$ postoperative time points in Group $\mathrm{H}$ compared with those in the other two groups (all $\mathrm{P}<0.05$; Fig. 2). Furthermore, the mechanical pain threshold in Group HDF at the three postoperative time points were all significantly higher compared with those of Group HD (all $\mathrm{P}<0.05$; Fig. 2).

VAS scores at $30 \mathrm{~min}$, and 1, 6, 12 and $24 \mathrm{~h}$ were higher in Group $\mathrm{H}$ than in the other two groups ( $\mathrm{P}<0.05$; Fig. 3). In addition, VAS scores at above time points were significantly lower in Group HDF than in the other two groups (all $\mathrm{P}<0.05$; Fig. 3).

Perioperative anesthetic parameters and perioperative anesthetic-related adverse events within $24 \mathrm{~h}$ after surgery. The time to first analgesic requirement was significantly shorter in Group H compared with the other two groups (both $\mathrm{P}<0.05$ ), and it was significantly longer in Group HDF compared with Group HD ( $\mathrm{P}<0.05$; Table II). The area of secondary hyperalgesia around the incision site at $24 \mathrm{~h}$ after surgery was greater in Group $\mathrm{H}$ than in the other two groups (both $\mathrm{P}<0.05$ ), and it was significantly smaller at $24 \mathrm{~h}$ after the surgery in Group HDF than in Group HD ( $\mathrm{P}<0.05$; Table II). The total sufentanil consumption was significantly higher in Group $\mathrm{H}$ at all time points than those in other two groups (all $\mathrm{P}<0.05)$ and significantly lower in Group HDF at these time points compared with those of Group HD (all $\mathrm{P}<0.05$; Table II).

The incidence of hypotension and bradycardia was significantly higher in Group HD when compared with Group H (both $\mathrm{P}<0.05$ ). Post-anesthetic shivering was significantly higher in Group H than in Group HD and Group HDF (both $\mathrm{P}<0.05)$. The incidence of PONV was significantly lower in Group HD than in Group H $(\mathrm{P}<0.05$; Table III).

\section{Discussion}

In the present study, the effects of combined dexmedetomidine and flurbiprofen axetil treatment on remifentanil-induced

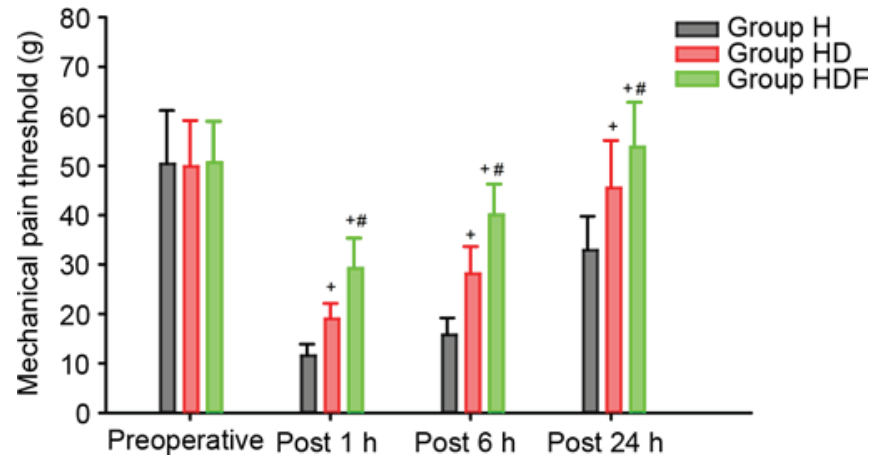

Figure 2. Peri-incisional mechanical pain threshold around the umbilicus Values are expressed as means and the error bars indicate standard deviation. Group $\mathrm{H}$, high dose of remifentanil $(0.3 \mu \mathrm{g} / \mathrm{kg} / \mathrm{min})$; Group HD, high dose of remifentanil $(0.3 \mu \mathrm{g} / \mathrm{kg} / \mathrm{min})$ plus dexmedetomidine; Group HDF: high dose of remifentanil $(0.3 \mu \mathrm{g} / \mathrm{kg} / \mathrm{min})$ plus dexmedetomidine and flurbiprofen axetil. ${ }^{+} \mathrm{P}<0.05$ vs. Group $\mathrm{H},{ }^{\text {"P }} \mathrm{P}<0.05$ vs. Group HD.

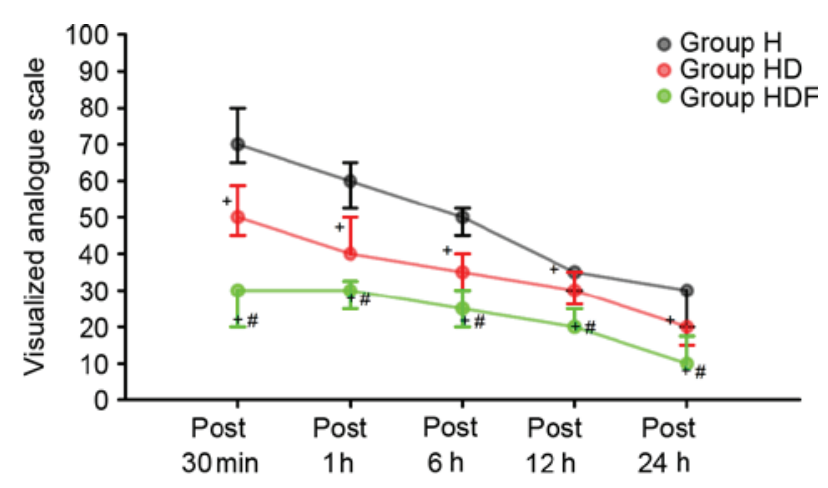

Figure 3. Postoperative pain scores measured with visualized analog scale values are expressed as medians and the error bars indicate the interquartile range. Group H, high dose of remifentanil ( $0.3 \mu \mathrm{g} / \mathrm{kg} / \mathrm{min})$; Group HD, high dose of remifentanil $(0.3 \mu \mathrm{g} / \mathrm{kg} / \mathrm{min})$ plus dexmedetomidine; Group HDF, high dose of remifentanil $(0.3 \mu \mathrm{g} / \mathrm{kg} / \mathrm{min})$ plus dexmedetomidine and flurbiprofen axetil. ${ }^{+} \mathrm{P}<0.05$ vs. Group $\mathrm{H},{ }^{\#} \mathrm{P}<0.05$ vs. Group HD.

hyperalgesia in patients undergoing LAVH were investigated. It was found that dexmedetomidine had protective effects against remifentanil-induced hyperalgesia, and the 
Table II. First analgesic requirement time, hyperalgesic area and sufentanil consumption during the postoperative $24 \mathrm{~h}$.

\begin{tabular}{|c|c|c|c|}
\hline Variables & Group H (n=29) & Group HD (n=28) & Group HDF $(n=29)$ \\
\hline First analgesic requirement (min) & $11.38 \pm 3.85$ & $22.18 \pm 6.46^{\mathrm{a}}$ & $54.14 \pm 14.83^{\mathrm{a}, \mathrm{b}}$ \\
\hline $\begin{array}{l}\text { Hyperalgesic area }\left(\mathrm{cm}^{2}\right) \\
\text { postoperative } 24 \mathrm{~h}\end{array}$ & $12.56(10.17-19.63)$ & $9.08(8.04-11.5)^{\mathrm{a}}$ & $3.14(3.14-4.52)^{\mathrm{a}, \mathrm{b}}$ \\
\hline \multicolumn{4}{|l|}{ Sufentanil consumption $(\mu \mathrm{g})$} \\
\hline Postoperative $30 \mathrm{~min}$ & $11.0(8.0-11.0)$ & $8.0(5.0-8.0)^{\mathrm{a}}$ & $0.0(0.0-0.0)^{\mathrm{a}, \mathrm{b}}$ \\
\hline Postoperative $1 \mathrm{~h}$ & $18.5(15.5-18.5)$ & $12.5(9.5-12.5)^{\mathrm{a}}$ & $1.5(1.5-4.5)^{\mathrm{a}, \mathrm{b}}$ \\
\hline Postoperative $6 \mathrm{~h}$ & $44.0(41.0-44.0)$ & $26.0(26.0-29.0)^{\mathrm{a}}$ & $15.0(11.3-15.0)^{\mathrm{a}, \mathrm{b}}$ \\
\hline Postoperative $12 \mathrm{~h}$ & $65.0(62.0-68.0)$ & $38.0(35.0-38.0)^{\mathrm{a}}$ & $27.0(24.0-27.0)^{\mathrm{a}, \mathrm{b}}$ \\
\hline Postoperative $24 \mathrm{~h}$ & $86.0(83.0-86.0)$ & $55.0(53.0-56.0)^{\mathrm{a}}$ & $45.0(42.0-45.0)^{\mathrm{a}, \mathrm{b}}$ \\
\hline
\end{tabular}

Values are expressed as mean \pm standard deviation or median (interquartile range). Group $\mathrm{H}$, high dose of remifentanil $(0.3 \mu \mathrm{g} / \mathrm{kg} / \mathrm{min})$; Group HD, high dose of remifentanil $(0.3 \mu \mathrm{g} / \mathrm{kg} / \mathrm{min})$ plus dexmedetomidine; Group HDF, high dose of remifentanil $(0.3 \mu \mathrm{g} / \mathrm{kg} / \mathrm{min}) \mathrm{plus}$ dexmedetomidine and flurbiprofen axetil. ${ }^{\mathrm{a}} \mathrm{P}<0.05$ vs. Group $\mathrm{H},{ }^{\mathrm{b}} \mathrm{P}<0.05$ vs. Group HD.

Table III. Perioperative anesthetic-related adverse events.

\begin{tabular}{lccc}
\hline Variables & Group H (n=29) & Group HD (n=28) & Group HDF (n=29) \\
\hline Hypotension perioperatively & $6(20.7)$ & $15(53.6)^{\mathrm{a}}$ & $14(48.3)$ \\
Bradycardia perioperatively & $7(24.1)$ & $16(57.1)^{\mathrm{a}}$ & $15(51.7)$ \\
Shivering within 1 h after surgery & $15(51.7)$ & $5(17.9)^{\mathrm{a}}$ & $4(13.8)^{\mathrm{a}}$ \\
PONV within 24 h postoperatively & $16(55.2)$ & $6(21.4)^{\mathrm{a}}$ & $7(24.1)$ \\
\hline
\end{tabular}

Values are expressed as number (\%). Group H, high dose of remifentanil ( $0.3 \mu \mathrm{g} / \mathrm{kg} / \mathrm{min})$; Group HD, high dose of remifentanil (0.3 $\mu \mathrm{g} / \mathrm{kg} / \mathrm{min})$ plus dexmedetomidine; Group HDF, high dose of remifentanil $(0.3 \mu \mathrm{g} / \mathrm{kg} / \mathrm{min})$ plus dexmedetomidine and flurbiprofen axetil. ${ }^{a} \mathrm{P}<0.05 \mathrm{vs}$. Group H.

combination of dexmedetomidine and flurbiprofen axetil had a synergetic effect in preventing the hyperalgesia induced by a high dose of remifentanil in patients undergoing $\mathrm{LAVH}$.

This conclusion was reached on the basis of the results obtained from the present study that a relatively large dose of intra-operative remifentanil induced postoperative hyperalgesia, which is revealed as a reduction of the postoperative peri-incisional mechanical pain threshold, an extension of secondary hyperalgesia, enhanced pain intensity, a shorter time to first postoperative analgesic requirement and high sufentanil consumption. Compared with patients in group $\mathrm{H}$, the patients in Group HD had a greater peri-incisional mechanical pain threshold, reduced area of secondary hyperalgesia, and lower VAS scores and sufentanil consumption. Furthermore, the mechanical pain threshold was much higher and the area of secondary hyperalgesia was much smaller in Group HDF compared with Group HD. In addition, VAS scores were significantly lower and sufentanil consumption was significantly less in Group HDF compared with Group HD.

Dexmedetomidine is a highly selective $\alpha_{2}$ adrenergic receptor agonist, acting on the central and peripheral nervous system, which possesses hypnotic, sedative, anxiolytic, sympatholytic, analgesic and antihyperalgesic characteristics (12). Studies have shown that dexmedetomidine produces an antihyperalgesic effect by suppressing the phosphorylation of the
NR2B subunit of the NMDA receptor (7) and increased tyrosine phosphorylation of NR2B in the spinal cord is associated with remifentanil-induced postoperative hyperalgesia (13). Dexmedetomidine also selectively inhibits excitatory postsynaptic potential via NMDA receptors, and inhibits synaptic transmission mediated by primary afferent $\mathrm{A}$ and $\mathrm{C}$ fibers to produce an antinociceptive effect (14). Moreover, dexmedetomidine has been shown to decrease hyperalgesia in neuropathic pain by increasing acetylcholine levels in the spinal cord (15) and suppressing glial cell proliferation of the spinal cord (16), which has been considered to amplify pain signals and activate the adjacent nerve cells involved in peripheral and central sensitization (17). A clinical study conducted by Lee et al (18) showed that dexmedetomidine administration reduced the hyperalgesia induced by high doses of remifentanil, and the findings of the present study are consistent with this. Dexmedetomidine was given at an initial dose of $0.5 \mu \mathrm{g} / \mathrm{kg}$ within $10 \mathrm{~min}$ prior to the induction of anesthesia, followed by a continuous infusion of $0.6 \mu \mathrm{g} / \mathrm{kg} / \mathrm{h}$ in the current study, instead of an initial dose of $1 \mu \mathrm{g} / \mathrm{kg}$ within $10 \mathrm{~min}$, followed by a continuous infusion of $0.7 \mu \mathrm{g} / \mathrm{kg} / \mathrm{h}$, which was a much higher dose. Furthermore, in the present study, sevoflurane was used as an induction agent instead of propofol, which has been reported to reduce OIH (19). Using the aforementioned optimized protocol, it was found that the relatively low dose of dexmedetomidine used in the present 
study was effective in reducing remifentanil-induced hyperalgesia, while a lower dose may reduce the incidence of the side effects such as bradycardia and hypotension. Therefore, a low dosage of dexmedetomidine could be a potential choice for physicians to use in their clinical practice to reduce the side effects and increase the tolerance of patients.

There have been many proposed mechanisms for OIH. Each type of inhibitor blocks only one of the several mechanisms involved in $\mathrm{OIH}$ and single drug administration may not be sufficient to effectively prevent hyperalgesia development. Based on this rational, a combination of dexmedetomidine and flurbiprofen axetil treatment was used in patients undergoing surgery in the present study, and it was found that the combination treatment had a synergetic effect in the prevention of remifentanil-induced hyperalgesia, supporting this hypothesis. Flurbiprofen axetil is a non-selective COX inhibitor carried in lipid microspheres, which has analgesic and anti-hyperalgesic effects through blocking spinal PG synthesis. Flurbiprofen axetil formulated in emulsified lipid microspheres has demonstrated a high affinity for inflammatory tissues to achieve targeted drug therapy and prolonged duration of action (20). PGs directly sensitize the spinal nociceptive system by depolarizing deep spinal cord dorsal horn neurons (21). Excessive release of excitatory amino acids has been reported to be associated with opioid-induced hyperalgesia (22) and PGs are able to stimulate the release of excitatory amino acid glutamate in spinal cord dorsal horns. Moreover, activation of NMDA receptors has found to be associated with the elevated COX-2 expression in the spinal dorsal horn upon the initiation of nociceptive stimulation (23). Therefore, inhibition of PG production would be expected to block opioid-induced hyperalgesia. Based on these previous findings, it may be proposed that flurbiprofen axetil exerted its relieving effects on remifentanil-induced postoperative hyperalgesia by reducing the synthesis and release of PG and inhibiting the activation of NMDA receptors by excitatory amino acids. A crossover study of healthy subjects suggested that both COX-1 and COX-2 inhibitors, but particularly COX-2 inhibitor, can relieve pinprick hyperalgesia (24). COX inhibitors are able to attenuate opioid-induced tolerance, hyperalgesia and dependence (25-27). To the best of our knowledge, the present study is the first to report that there was a notably decreased hyperalgesic area, a predicting factor for the development of chronic postsurgical pain (28), in hyperalgesic patients treated with dexmedetomidine and flurbiprofen axetil. Therefore, this study has not only demonstrated for the first time the effect of flurbiprofen axetil in decreasing the hyperalgesic area, but has also suggested a possible pathway through which hyperalgesia could be prevented.

The QST protocol was established by the German Network on Neuropathic Pain to investigate the somatosensory thresholds in healthy subjects and in patients with neuropathic pain (29). However, most studies have used indirect evidence, such as greater postoperative pain and analgesic consumption for evaluating $\mathrm{OIH}$, which might be less sensitive and objective than QST. Previous studies of hyperalgesia have used QST performed with traditional von Frey Monofilaments (VFMs) $(11,18,30)$. In the present study, an EVF device was used for quantitative sensory testing to explore mechanical hyperalgesia, which is more reliable and rapid than traditional VFM in exploring mechanical pain thresholds (31). Using this methodology, it was found that the incidence of hypotension and bradycardia in Group HD and Group HDF was higher than that in Group H. Therefore, dexmedetomidine combined with a high dose of remifentanil should be used with caution. Furthermore, it is important to determine an optimized infusion rate of dexmedetomidine that could maximize the anesthetic and analgesic-sparing effect, while minimizing the incidence of adverse cardiovascular side effects.

Dexmedetomidine also showed a significant antiemetic effect, which could be explained by the direct antiemetic effect of $\alpha_{2}$ adrenergic receptor agonists due to a decreased level of catecholamine and/or its opioid-sparing effect. In this study, it was found that post-anesthetic shivering was associated with high-dose remifentanil and could be prevented by dexmedetomidine. The anti-shivering action of dexmedetomidine results from reduced vasoconstriction and an increase in the shivering threshold (32). A previous study has demonstrated that parecoxib administered $30 \mathrm{~min}$ prior to the induction of anesthesia effectively reduced the incidence and severity of remifentanil-induced shivering (33). However, whether flurbiprofen axetil has a protective effect against post-anesthetic shivering requires further investigation.

There were several limitations in this study. First, the effect of flurbiprofen axetil alone on the prevention of $\mathrm{OIH}$ requires further investigation. Secondly, the usage of a background infusion might decrease the sensitivity to sufentanil consumed during the observation period. However, since the dosage of sufentanil was only $1.5 \mu \mathrm{g} / \mathrm{h}$, the impact should be minimal. Finally, it would also be interesting to study the synergetic effect of combined dexmedetomidine and flurbiprofen axetil treatment in patients receiving major open surgery.

In summary, high doses of intra-operative remifentanil are associated with postoperative hyperalgesia, which is efficiently alleviated or even prevented by dexmedetomidine or co-administration of flurbiprofen axetil. This synergetic effect could also help to reduce the usage of remifentanil during surgery to further prevent its excessive use resulting in OIH. Flurbiprofen axetil (COX inhibitor) decreased the secondary hyperalgesia that may contribute to the development of chronic pain. Therefore, the use of a combination of dexmedetomidine and COX inhibitor as an adjunctive agent to propofol-remifentanil-based general anesthesia might be a promising method for preventing or attenuating $\mathrm{OIH}$.

\section{Acknowledgements}

The authors would like to thank the staff from the department of Gynecology in Fujian Provincial Hospital for their support and cooperation.

\section{References}

1. Wu CL and Raja SN: Treatment of acute postoperative pain. Lancet 377: 2215-2225, 2011.

2. Angst MS and Clark JD: Opioid-induced hyperalgesia: A qualitative systematic review. Anesthesiology 104: 570-587, 2006.

3. Fletcher D and Martinez V: Opioid-induced hyperalgesia in patients after surgery: A systematic review and a meta-analysis. Br J Anaesth 112: 991-1004, 2014.

4. Lee M, Silverman SM, Hansen H, Patel VB and Manchikanti L: A comprehensive review of opioid-induced hyperalgesia. Pain Physician 14: 145-161, 2011. 
5. Zhao M and Joo DT: Enhancement of spinal N-methyl-D-aspartate receptor function by remifentanil action at delta-opioid receptors as a mechanism for acute opioid-induced hyperalgesia or tolerance. Anesthesiology 109: 308-317, 2008.

6. Chu LF, Angst MS and Clark D: Opioid-induced hyperalgesia in humans: Molecular mechanisms and clinical considerations. Clin J Pain 24: 479-496, 2008.

7. Zheng Y, Cui S, Liu Y, Zhang J, Zhang W, Zhang J, Gu X and Ma Z: Dexmedetomidine prevents remifentanil-induced postoperative hyperalgesia and decreases spinal tyrosine phosphorylation of N-methyl-d-aspartate receptor 2B subunit. Brain Res Bull 87: 427-431, 2012.

8. Tröster A, Sittl R, Singler B, Schmelz M, Schüttler J and Koppert W: Modulation of remifentanil-induced analgesia and postinfusion hyperalgesia by parecoxib in humans. Anesthesiology 105: 1016-1023, 2006.

9. O'Rielly DD and Loomis CW: Increased expression of cyclooxygenase and nitric oxide isoforms, and exaggerated sensitivity to prostaglandin E2, in the rat lumbar spinal cord 3 days after L5-L6 spinal nerve ligation. Anesthesiology 104: 328-337, 2006

10. Ahmadi S, Muth-Selbach U, Lauterbach A, Lipfert P, Neuhuber WL and Zeilhofer HU: Facilitation of spinal NMDA receptor currents by spillover of synaptically released glycine. Science 300: 2094-2097, 2003.

11. Joly V, Richebe P, Guignard B, Fletcher D, Maurette P, Sessler DI and Chauvin M: Remifentanil-induced postoperative hyperalgesia and its prevention with small-dose ketamine. Anesthesiology 103: 147-155, 2005.

12. Blaudszun G, Lysakowski $\mathrm{C}$, Elia $\mathrm{N}$ and Tramèr MR: Effect of perioperative systemic $\alpha 2$ agonists on postoperative morphine consumption and pain intensity: Systematic review and meta-analysis of randomized controlled trials. Anesthesiology 116: 1312-1322, 2012

13. Gu X, Wu X, Liu Y, Cui S and Ma Z: Tyrosine phosphorylation of the N-Methyl-D-Aspartate receptor 2B subunit in spinal cord contributes to remifentanil-induced postoperative hyperalgesia: The preventive effect of ketamine. Mol Pain 5: 76, 2009.

14. Faber ES, Chambers JP and Evans RH: Depression of NMDA receptor-mediated synaptic transmission by four alpha2 adrenoceptor agonists on the in vitro rat spinal cord preparation. $\mathrm{Br} \mathrm{J}$ Pharmacol 124: 507-512, 1998.

15. Kimura M, Saito S and Obata H: Dexmedetomidine decreases hyperalgesia in neuropathic pain by increasing acetylcholine in the spinal cord. Neurosci Lett 529: 70-74, 2012.

16. Xu B, Zhang WS, Yang JL, Lû N, Deng XM, Xu H and Zhang YQ: Evidence for suppression of spinal glial activation by dexmedetomidine in a rat model of monoarthritis. Clin Exp Pharmacol Physiol 37: e158-e166, 2010.

17. Liu L, Ji F, Liang J, He H, Fu Y and Cao M: Inhibition by dexmedetomidine of the activation of spinal dorsal horn glias and the intracellular ERK signaling pathway induced by nerve injury. Brain Res 1427: 1-9, 2012.

18. Lee C, Kim YD and Kim JN: Antihyperalgesic effects of dexmedetomidine on high-dose remifentanil-induced hyperalgesia. Korean J Anesthesiol 64: 301-307, 2013.
19. Singler B, Tröster A, Manering N, Schüttler J and Koppert W: Modulation of remifentanil induced postinfusion hyperalgesia by propofol. Anesth Analg 104: 1397-1403, 2007.

20. Ohmukai O: Lipo-NSAID preparation. Adv Drug Deliv Rev 20: 203-207, 1996.

21. Baba H, Kohno T, Moore KA and Woolf CJ: Direct activation of rat spinal dorsal horn neurons by prostaglandin E2. J Neurosci 21: 1750-1756, 2001.

22. Wen $\mathrm{ZH}$, Chang YC, Cherng CH, Wang JJ, Tao PL and Wong CS: Increasing of intrathecal CST excitatory amino acids concentration following morphine challenge in morphine-tolerant rats. Brain Res 995: 253-259, 2004.

23. Li SQ, Xing YL, Chen WN, Yue SL, Li L and Li WB: Activation of NMDA receptor is associated with up-regulation of COX-2 expression in the spinal dorsal horn during nociceptive inputs in rats. Neurochem Res 34: 1451-1463, 2009.

24. Lenz H, Raeder J, Draegni T, Heyerdahl F, Schmelz M and Stubhaug A: Effects of COX inhibition on experimental pain and hyperalgesia during and after remifentanil infusion in humans. Pain 152: 1289-1297, 2011.

25. Akbari E: The role of cyclo-oxygenase inhibitors in attenuating opioid-induced tolerance, hyperalgesia, and dependence. Med Hypotheses 78: 102-106, 2012.

26. Koppert W, Wehrfritz A, Körber N, Sittl R, Albrecht S, Schüttler J and Schmelz M: The cyclooxygenase isozyme inhibitors parecoxib and paracetamol reduce central hyperalgesia in humans. Pain 108: 148-153, 2004.

27. Tröster A, Sittl R, Singler B, Schmelz M, Schüttler J and Koppert W: Modulation of remifentanil-induced analgesia and postinfusion hyperalgesia by parecoxib in humans. Anesthesiology 105: 1016-1023, 2006 .

28. Hinrichs-Rocker A, Schulz K, Järvinen I, Lefering R, Simanski C and Neugebauer EA: Psychosocial predictors and correlates for chronic post-surgical pain (CPSP)-a systematic review. Eur J Pain 13: 719-730, 2009.

29. Rolke R, Baron R, Maier C, Tölle TR, Treede RD, Beyer A, Binder A, Birbaumer N, Birklein F, Bötefür IC, et al: Quantitative sensory testing in the German Research Network on Neuropathic Pain (DFNS): Standardized protocol and reference values. Pain 123: 231-243, 2006.

30. Lee C, Lee HW and Kim JN: Effect of oral pregabalin on opioid-induced hyperalgesia in patients undergoing laparo-endoscopic single-site urologic surgery. Korean J Anesthesiol 64: 19-24, 2013

31. Tena B, Escobar B, Arguis MJ, Cantero C, Rios J and Gomar C: Reproducibility of Electronic Von Frey and Von Frey monofilaments testing. Clin J Pain 28: 318-323, 2012.

32. Bajwa SJ, Gupta S, Kaur J, Singh A and Parmar S: Reduction in the incidence of shivering with perioperative dexmedetomidine: A randomized prospective study. J Anaesthesiol Clin Pharmacol 28: 86-91, 2012.

33. Elmawgood AA, Rashwan S and Rashwan D: Effect of parecoxib on remifentanil induced postoperative shivering. Egypt J Anaesthesiol 30: 399-403, 2014 